Case Report

\title{
Two Phase Therapy for Class II Division 1 Malocclusion - A Case Report
}

\section{Suraj Prasad Sinha ${ }^{1}$, Akhil Shetty ${ }^{2}$, M.S. Ravi ${ }^{3}$, U.S. Krishna Nayak ${ }^{4}$}

${ }^{1}$ PG Student, ${ }^{2}$ Reader, ${ }^{3}$ Professor \& Head of the Department, ${ }^{4}$ Senior Professor, Principal \& Dean, Department of Orthodontics and Dento-facial Orthopedics, A.B. Shetty M emorial Institute of Dental Sciences, M angalore.

*Corresponding Author : Suraj Prasad Sinha, Post Graduate student, Department of Orthodontics and Dento-facial Orthopedics, A.B. Shetty M emorial Institute of Dental Sciences, M angalore.

$\begin{array}{ll}\text { Received } & : 28.07 .2017 \\ \text { Review Completed } & : 08.08 .2017 \\ \text { Accepted } & : 10.08 .2017\end{array}$

Keywords : Two phase therapy, Twin block, Self ligating bracket, Mandibular advancement, VTO.

\begin{abstract}
A 13 year old growing male reported with a complaint of forwardly placed upper front teeth. The case was diagnosed to be Skeletal Class II due to retrognathic mandible. Since the patient was in the growing phase, two phase treatment was planned. The First phase comprised of mandibular advancement using TWIN BLOCK. The final finishing and detailing was achieved in the Second phase of treatment using $0.022 \mathrm{M} \mathrm{BT}$ Prescription (self-legating) to produce well-aligned arches in good function and aesthetics.
\end{abstract}

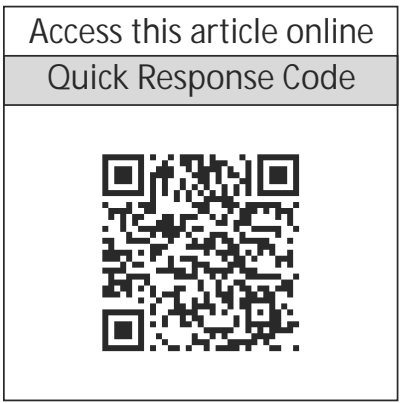

\section{Introduction}

The malocclusion and dento-facial deformity in most instances are caused not by some pathological process but by moderate distortions of normal development. The majority of Class II malocclusions present with a laterally contracted maxilla that is often related correctly to the cranial base but is associated with an underdeveloped mandible. The fundamental skeletal problem is not correctly addressed by an approach which is designed to retract a normal maxilla to match a deficient mandible.

The concept of Functional therapy is to expand and develop the upper arch to improve arch form, and to use the maxilla as a template against which to reposition the retrusive mandible in a correct relationship to the normal maxilla. The functional matrix theory of Moss (1968) supports the premise that function modifies anatomy.

Twin block appliances are simple bite blocks that are designed for full-time wear. They achieve rapid functional correction of malocclusion by the transmission of favorable occlusal forces to occlusal inclined planes that cover the posterior teeth. The proprioceptive sensory feedback mechanism control muscular activity and provides a functional stimulus or deterrent to the full expression of mandibular bone growth.

\section{Case Report}

A 13 year old growing male reported to our department with the chief complaint of forwardly placed upper front teeth. On extra oral examination, patient was having convex profile, leptoprosopic facial index with incompetent lips, recessive chin and deep mentolabial sulcus.

On intra oral examination, all 28 teeth were present (with partially erupted 37, 47; except the third molars). The molar relationship was Angle's Class II, the Canine relationship was Class II and the Incisor relationship was Class II Div 1 with overjet of $14 \mathrm{~mm}$, severe crowding in the 
mandibular anterior and $100 \%$ of overbite.
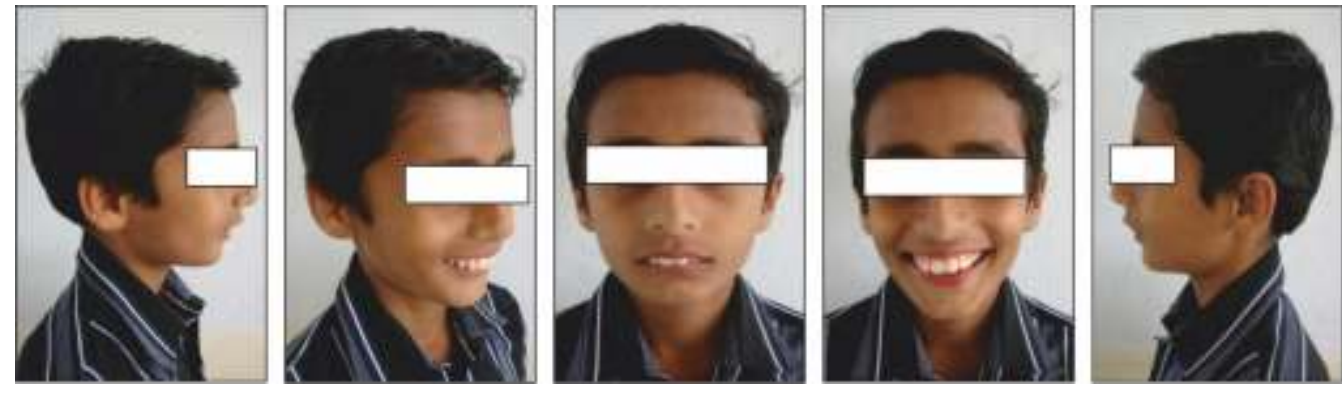

Figure Showing Pre Treatment extra Oral Photographs
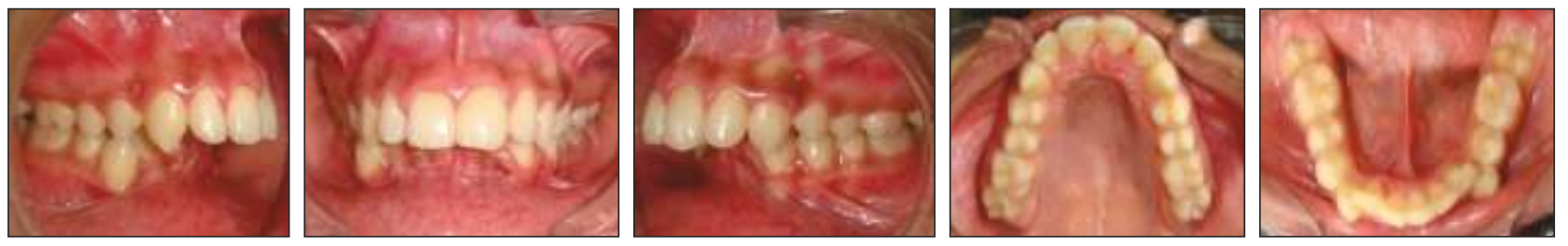

Figure Showing Pre Treatment intra Oral Photographs

The radiographic examination revealed that the patient was having Skeletal Class II malocclusion due to retrognathic mandible with average growth pattern. The angle of convexity was 14 @due to severely recessive chin.
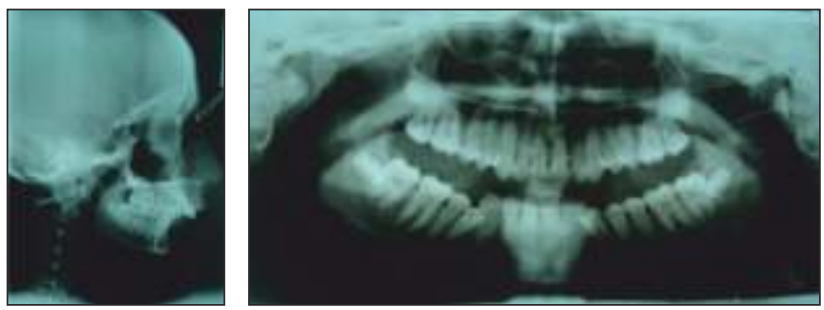

Figure Showing Pre Treatment lateral Cephalogram and OPG

\section{Diagnosis}

Growing male patient having Skeletal Class II malocclusion due to retrognathic mandible and average growth pattern.

\section{Treatment Objectives}

- Correction of Class II Skeletal relationship

- Correction of overjet and overbite.

- Achieve Class I molar and canine relationship.

- Correction of mandibular anterior crowding.

- Achieve optimal facial balance and esthetics.

\section{Treatment Plan}

The VTO (Visual Treatment Objective) photograph was taken which clearly shows that the patient's profile improves a lot by bringing the mandible forward.
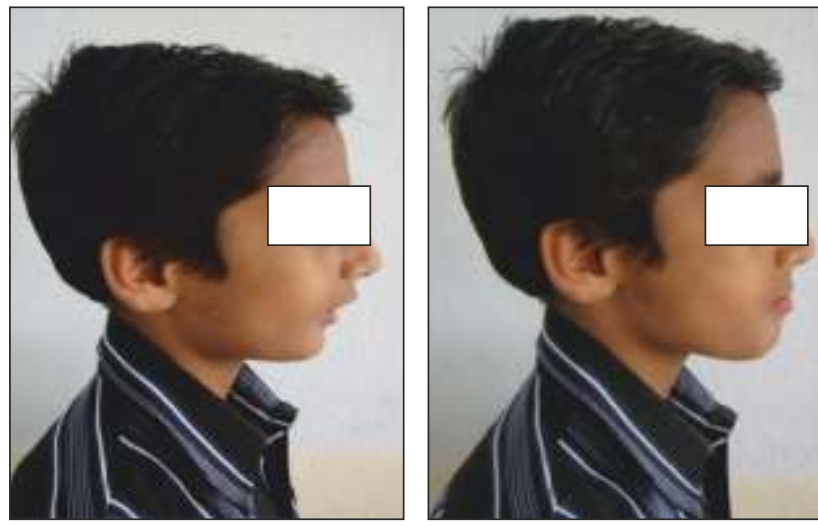

Since the patient was a 13 year old male, we went on to check the Growth status of the patient by taking the HandWrist Radiograph.

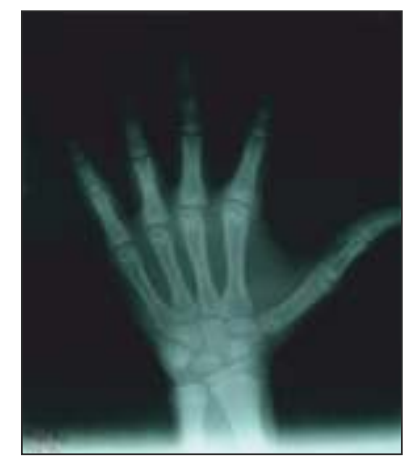

The Hand - Wrist Radiograph clearly shows that there is around $50-60 \%$ of the growth remaining. And hence advancing the mandible using a Functional Appliance will be of great advantage at this age.

Hence the treatment plan was finalized with TWO PHASE Therapy:

First Phase : The Growth M odification Using TWIN BLOCK

Second Phase : PEA - 0.022 M BT Prescription (Self - Ligating) brackets.

* The advancement in the First Phase was planned in TWO steps as the overjet was $14 \mathrm{~mm}$. 


\section{First Phase}

With the appliances in the mouth, the patient cannot occlude comfortably in the former distal position and the mandible is encouraged to adopt a protrusive bite with the inclined planes engaged in occlusion. Twin block are designed to be worn 24 hours per day to take full advantage of all functional forces applied to the dentition, including the forces of mastication. Upper and lower bite blocks interlock at a 70 kangle when engaged in full closure. This causes a forward mandibular posture to an edge to edge position with the upper anteriors, provided the patient can comfortably maintain full occlusion on the appliances in that position.
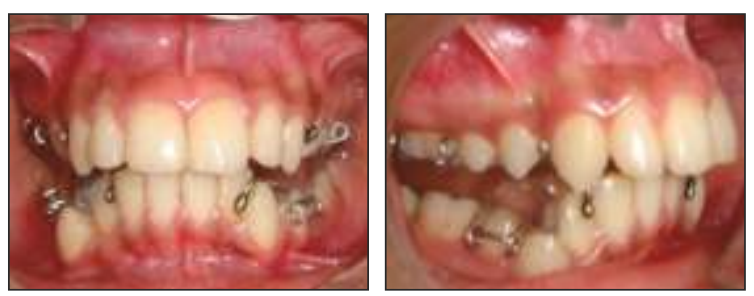

Figure Showing the Initial Advancement during the First Phase
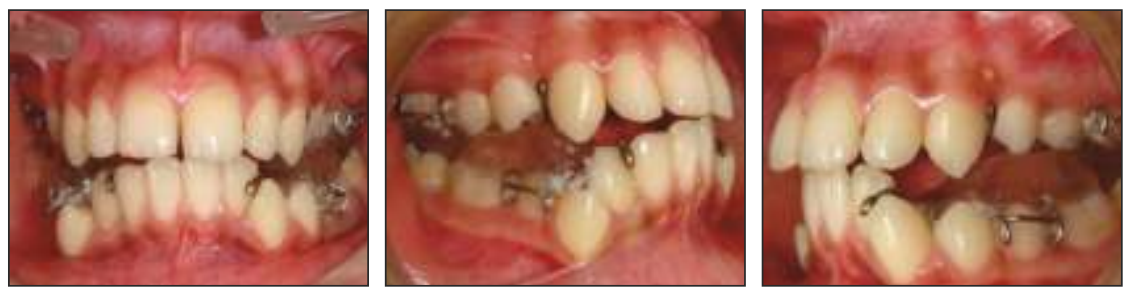

Figure Showing the Final Advancement during the First Phase

Post Twin Block Phase Outcome
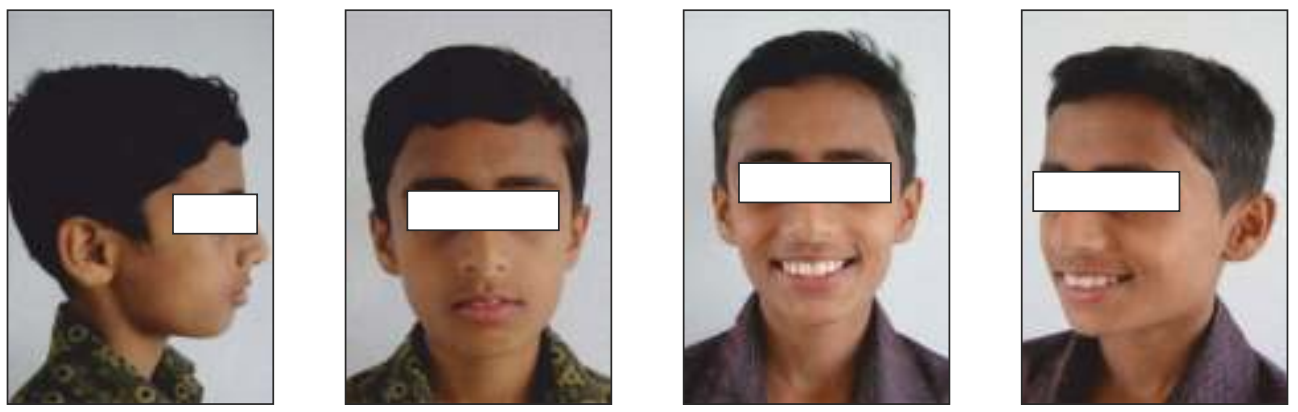

Figure Showing Extra Oral Photographs
The initial advancement in the Growth Phase done was approximately $7-8 \mathrm{~mm}$ of the total $14 \mathrm{~mm}$. Larger overjets invariably require partial correction, followed by reactivation after the initial partial correction is accomplished.

The final advancement was in such a way so that there is Edge to Edge Incisor relationship was achieved.
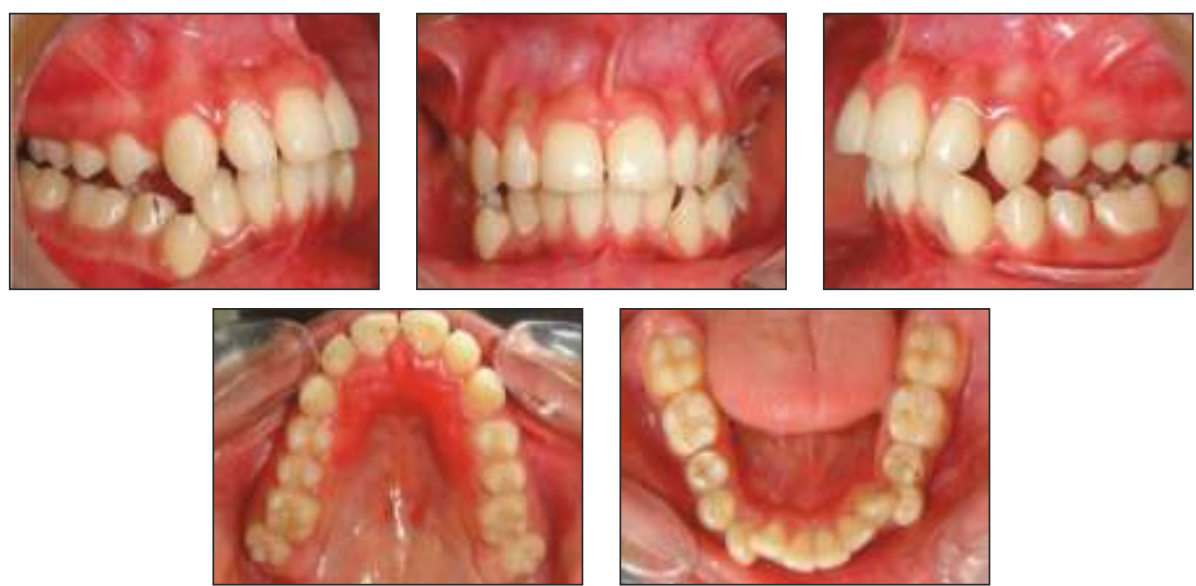

Intra oral Figure Showing Banded and Bonded Upper and Lower Arches 

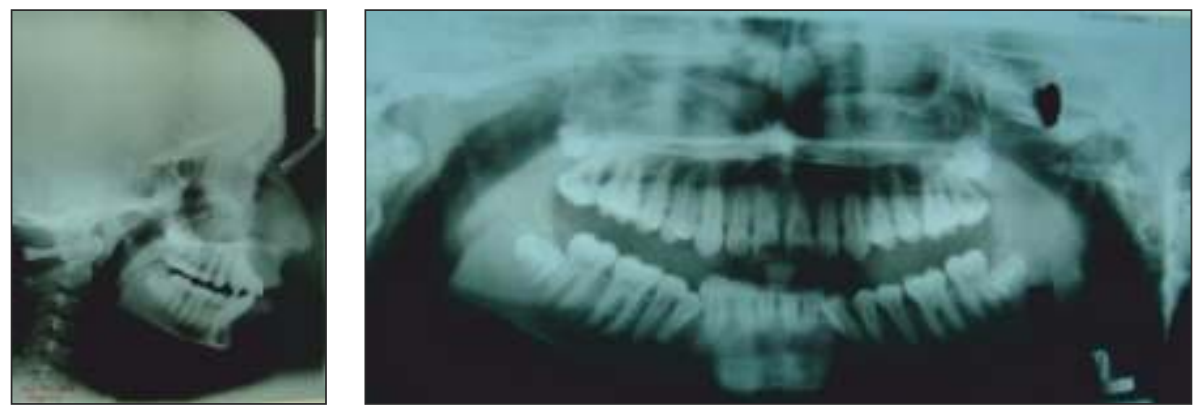

Figure Showing Lateral Cephalogram and OPG

Second Phase started with the strap up of the upper and lower arches with 0.022 M BT slot (Self Ligating) brackets.
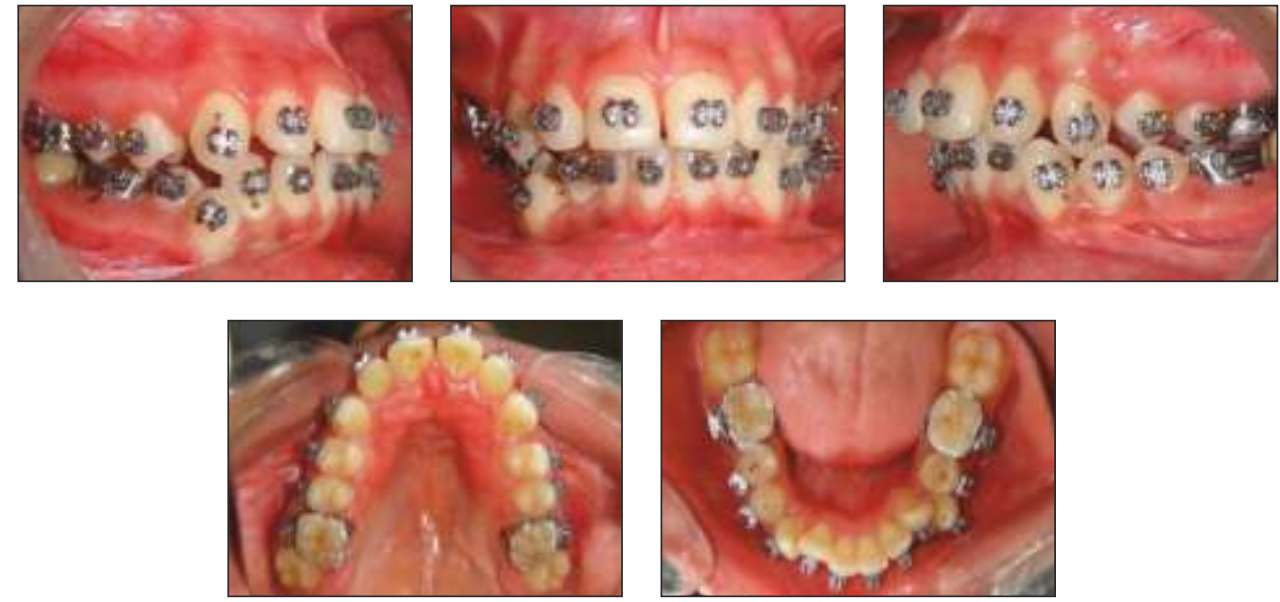

Intra oral Figure Showing Banded and Bonded Upper and Lower Arches

\section{Post Treatment Outcome}

The comparison of skeletal and dental changes in the pre- and post- treatment condition is summed up in the table while the lateral extra oral photographic comparison of pre- and post- treatment results shows significant improvement. The treatment results show significant improvement in the patients' stomatognathic system with best possible function and aesthetics.
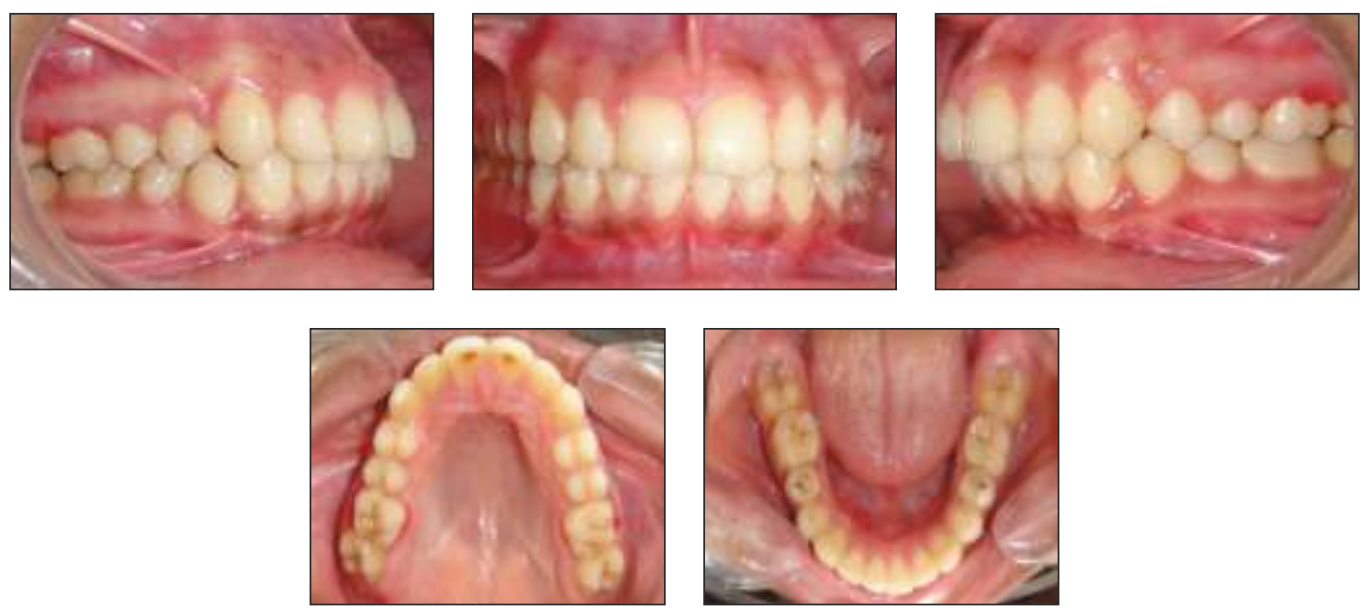

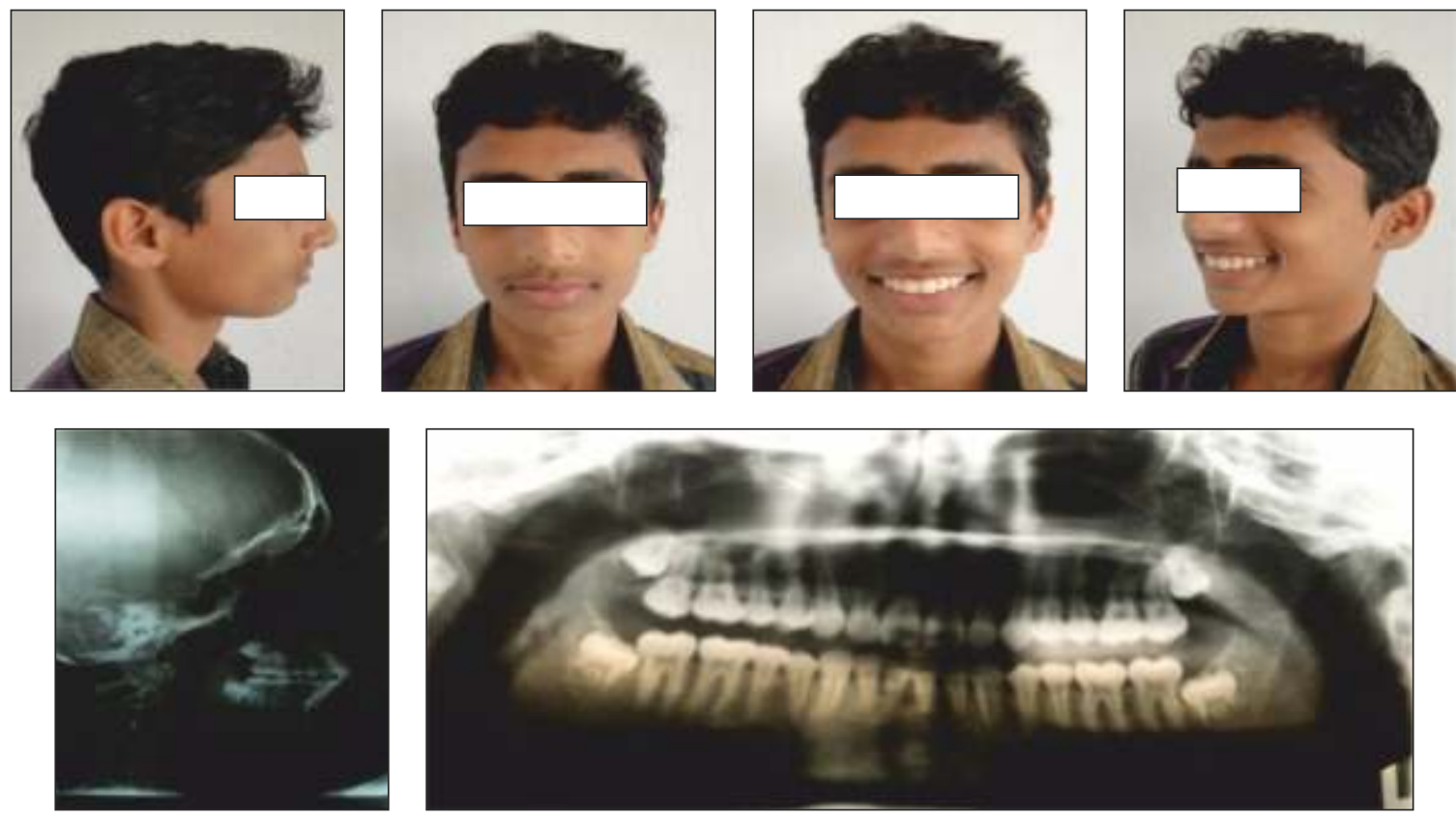

Relevant Cephalometric Values

\begin{tabular}{|l|c|c|c|}
\hline Cephalometric Values & Pre treatment & M id Treatment & Post treatment \\
\hline SNA & $75^{\circ}$ & $74^{\circ}$ & 73 \\
\hline SNB & $67^{\circ}$ & $71^{\circ}$ & $70^{\circ}$ \\
\hline WITS & $5.5 \mathrm{~mm}$ & $-2 \mathrm{~mm}$ & $-1 \mathrm{~mm}$ \\
\hline N-A-Pg & $14^{\circ}$ & $4^{\circ}$ & $5^{\circ}$ \\
\hline Upper Incisor to NA & $30^{\circ} / 7 \mathrm{~mm}$ & $32^{\circ} / 8 \mathrm{~mm}$ & $31^{\circ} / 7 \mathrm{~mm}$ \\
\hline Lower Incisor to NB & $17^{\circ} / 3 \mathrm{~mm}$ & $34^{\circ} / 9 \mathrm{~mm}$ & $38^{\circ} / 8 \mathrm{~mm}$ \\
\hline Lower incisor to M and. plane & $95^{\circ}$ & $112^{\circ}$ & 115 \\
\hline Inter-incisal Angle & $125^{\circ}$ & $115^{\circ}$ & $115^{\circ}$ \\
\hline Nasolabial Angle & $110^{\circ}$ & $113^{\circ}$ & 115 \\
\hline Upper lip to E line & $0 \mathrm{~mm}$ & $-2 \mathrm{~mm}$ & $-2 \mathrm{~mm}$ \\
\hline Lower lip to E line & $5 \mathrm{~mm}$ & $2 \mathrm{~mm}$ & $2 \mathrm{~mm}$ \\
\hline Upper lip to S line & $3 \mathrm{~mm}$ & $2 \mathrm{~mm}$ & $0 \mathrm{~mm}$ \\
\hline Lower lip to Sline & $-3 \mathrm{~mm}$ & $4 \mathrm{~mm}$ & $3 \mathrm{~mm}$ \\
\hline
\end{tabular}

Retention Phase

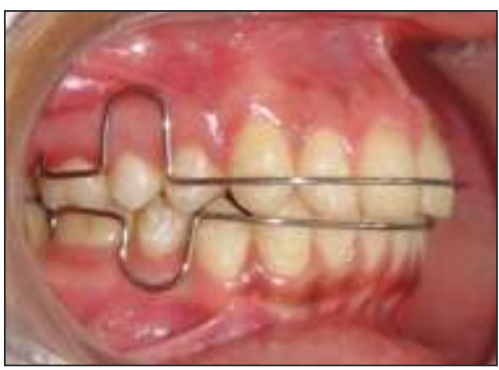

The patient is in the retention phase for past 6 months with WRAP around retainers.

\section{References}

1. Proffit WR. The etiology of orthodontic problems. In : Proffit WR, Fields HW, Sarver DM, editors. Contemporary Orthodontics. $4^{\text {th }}$ ed. St. louis: Mosby; 2007.

2. M oss, M L. the primacy of functional matrices in profacial growth, Dent Pract, 1968, 19: 65-73.

3. ClarkWJ. Twin Block Functional Therapy. $2^{\text {nd }}$ ed. M osby; 2002.

4. De Vicenzo, JP \& Winn, MW (1989). Orthopaedic and orthodontic effectsresulting from the use of a functional appliance with different amount of protrusive activation. Am. J. Orthod. Orthop. 96: 181-190.

5. Falke, F \& Frankel, R (1989) Clinical relevance of step by step mandibular advancement in the treatment of mandibular retrusion using the Frankel appliance. Am. J. Orthod. Dentofac. Orthop., 96: 33341. 